\title{
CARACTERIZAÇÃO HIDROQUÍMICA DO SISTEMA AQUÍFERO SERRA GERAL NA REGIÃO NORDESTE DO RIO GRANDE DO SUL
}

\author{
HYDROCHEMICAL CHARACTERIZATION OF SERRA GERAL AQUIFER \\ SYSTEM IN NORTHEAST REGION OF RIO GRANDE DO SUL
}

\author{
Pedro Antonio Roehe Reginato ${ }^{1}$, Siclério Ahlert ${ }^{2}$, Vania Elisabete Schneider ${ }^{3}$
}

Artigo recebido em: 18/05/2012 e aceito para publicação em: 14/12/2012

\begin{abstract}
This paper presents the hydrochemical characterization of the Serra Geral Aquifer System (SASG), identifying some typical patterns for this unit, as well as evidence indicating the possible hydraulic connection with the Guarani Aquifer System (SAG). This study was developed in the northeast region of the Rio Grande do Sul state and involved the evaluation of physical-chemical parameters, also Stiff and Piper diagrams. In the region SAG is a confined aquifer, associated with sedimentary rocks of the Botucatu Formation, with sodium bicarbonate, calcium or magnesium bicarbonate and sodium sulfated groundwater, and higher values for $\mathrm{pH}$ (7.9 to 9.6) and conductivity ( 270 to $686 \mathrm{uS} / \mathrm{cm}$ ), while the SASG is associated with volcanic rocks of the Serra Geral Formation and its waters are calcium or magnesium bicarbonate, with varying concentrations of calcium, magnesium, sodium, carbonates, bicarbonates, conductivity below $200 \mathrm{uS} / \mathrm{cm}$ and $\mathrm{pH}$ lower than 7.5. However, occurrences of the waters in SASG classified as a sodium bicarbonate and sulfated calcium or magnesium, associated with the increase in the concentration of sodium, potassium, carbonates, bicarbonates, chlorides, sulfates, $\mathrm{pH}$ and electrical conductivity, seems to indicate the possibility of a connection between the two units, which can exist in regions where there is a greater degree of fracturing and thinner package of volcanic rocks.
\end{abstract}

Keywords: Hydrochemical. Hidrogeology. Serra Geral Aquifer. Guarani Aquifer.

Resumo: Este artigo apresenta a caracterização hidroquímica do Sistema Aquífero Serra Geral (SASG), identificando alguns padrões típicos para essa unidade, bem como indícios que apontam para uma possível conexão hidráulica com o Sistema Aquífero Guarani (SAG). Esse estudo foi desenvolvido na região nordeste do Estado do Rio Grande do Sul e envolveu a avaliação de parâmetros físicos, químicos e dos diagramas de Piper e Stiff. Na região, o SAG é um aquífero confinado, associado às rochas sedimentares da Formação Botucatu, com águas bicarbonatadas sódicas, bicarbonatadas cálcicas ou magnesianas, sulfatadas sódicas e valores mais elevados para pH $(7,9$ a 9,6) e condutividade (270 a 686 uS/cm), enquanto o SASG está associado às rochas vulcânicas da Formação Serra Geral e suas águas são bicarbonatadas cálcicas ou magnesianas, com concentrações variáveis de cálcio, magnésio, sódio, carbonatos, bicarbonatos, condutividade inferiores a $200 \mathrm{uS} / \mathrm{cm}$ e pH menores que 7,5. No entanto, ocorrências de águas no SASG classificadas como bicarbonatadas sódicas a sulfatadas cálcicas ou magnesianas, associadas ao aumento na concentração de sódio, potássio, carbonatos, bicarbonatos, cloretos, sulfatos, $\mathrm{pH}$ e condutividade elétrica, parece indicar a possibilidade de existência de uma conexão entre as duas unidades, que pode existir nas regiões onde há maior grau de fraturamento e menor espessura do pacote de rochas vulcânicas.

Palavras-Chave: Hidroquímica. Hidrogeologia. Aquífero Serra Geral. Aquífero Guarani.

\section{INTRODUÇÃO}

$\mathrm{Na}$ região nordeste do estado do Rio Grande do Sul, os recursos hídricos subterrâneos estão associados ao Sistema Aquífero Serra Geral (SASG) e ao Sistema Aquífero Guarani (SAG). O SASG representa um típico aquífero fraturado associado às rochas vulcânicas da Formação Serra Geral, condicionados por estruturas tectônicas (fraturas e zonas de fraturas) e estruturas primárias (zonas de brechas, vesiculares a amigdalói- des, de diáclases ou disjunção horizontal e vertical), enquanto o SAG está associado às rochas sedimentares, pertencentes principalmente à Formação Botucatu, podendo ser considerado um aquífero granular com porosidade primária, mas influenciado por estruturas tectônicas que dão origem a uma porosidade secundária e a possibilidade de conexão com o SASG. Além disso, o SAG é confinado pelas rochas vulcânicas ácidas

\footnotetext{
${ }^{1}$ Universidade Federal do Rio Grande do Sul (pedro.reginato@ufrgs.br).

2 Universidade de Caxias do Sul (siclerio@yahoo.com.br).

${ }^{3}$ Universidade de Caxias do Sul (veschnei@ucs.br).
} 
(entre 50 e $850 \mathrm{~m}$ ) apresentando diferentes graus de confinamento.

As águas que circulam por esses dois sistemas aquíferos apresentam características hidroquímicas variadas. Essa diferenciação depende do tipo de aquífero, da existência de conexão entre os aquíferos e do grau de confinamento.

Este trabalho apresenta as características e padrões hidroquímicos das águas subterrâneas do Sistema Aquífero Serra Geral (SASG), bem como avalia a possibilidade de ocorrência da influência do Sistema Aquífero Guarani (SAG) no comportamento hidroquímico do SASG.

\section{LOCALIZAÇÃO}

A área de estudo está localizada na região nordeste do estado do Rio Grande do Sul, no setor central da bacia hidrográfica Taquari-Antas. Os dados hidrogeológicos, utilizados nesse estudo, foram obtidos a partir de poços tubulares localizados no território de 15 municípios (Figura 1).

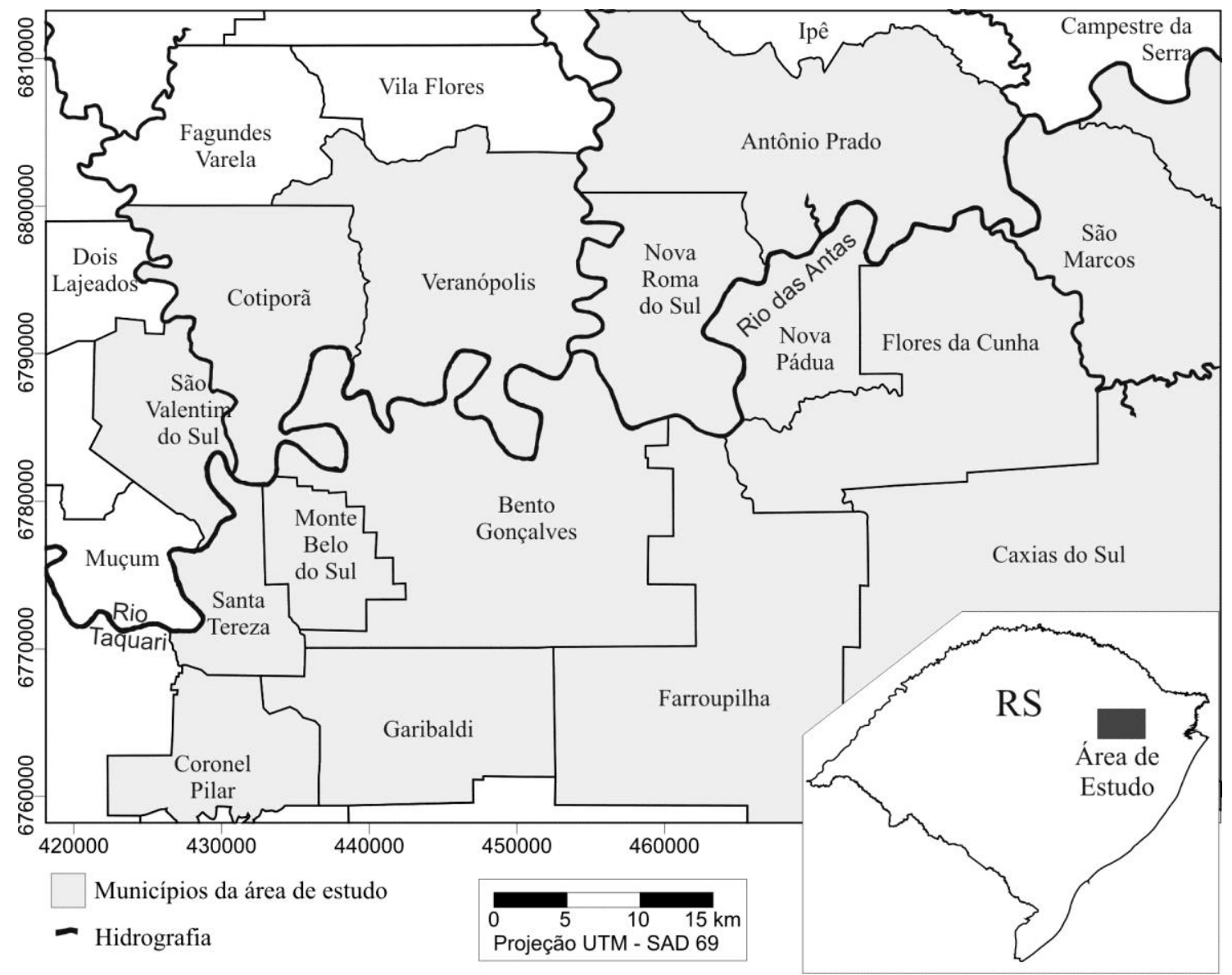

Figura 1 - Localização da área de estudo.

Figure 1 - Location of the study area.

\section{MATERIAIS E MÉTODOS}

As etapas de trabalho que permitiram a caracterização hidroquímica do SASG na porção nordeste do estado do Rio Grande do Sul, englobando os municípios de Santa Tereza, Monte Belo do Sul, Bento Gonçalves e Veranópolis envolveram a realização do: inventário e cadastramento de poços tubulares, levantamento e interpretação de dados geológicos e hidrgeo- lógicos, avaliação de análises químicas disponíveis e coleta de amostras de água.

A seleção da região deve-se a variabilidade na espessura do pacote de rochas vulcânicas que recobrem as rochas sedimentares da Formação Botucatu (entre 50 e 700 metros).

A etapa de inventário e cadastramento de poços foi realizada inicialmente com o levanta- 
mento de dados existentes junto ao banco de dados de informações de águas subterrâneas do Serviço Geológico do Brasil (SIAGAS-CPRM), companhias de abastecimento, prefeituras municipais, empresas de perfuração e usuários. Desse levantamento foram cadastrados 973 poços tubulares na área de estudo, dos quais 192 poços possuíam dados de análises físico-químicas e bacteriológicas.

O levantamento de dados geológicos e hidrogeológicos existentes na região, foi realizado por meio da análise de mapas, relatórios, teses e artigos, bem como de levantamentos de campo (descrição de rochas e estruturas), além da interpretação de relatórios de perfuração de poços tubulares (perfis geológicos e construtivos). Os dados geológicos e hidrogeológicos apresentados por Reginato (2003), Reginato e Strieder (2006a e 2006b) serviram de base para o trabalho. Todas essas informações foram integradas com o emprego do programas de geoprocessamento IDRISI, CARTALINX e GVSig, que permitiram a geração de mapas com a distribuição dos poços e sua relação com a geologia e hidrogeologia, auxiliando na identificação de poços tubulares que captam água do SASG e de poços tubulares que captam água do SAG.

$\mathrm{O}$ tratamento das análises químicas e bacteriológicas iniciou-se com a identificação dos parâmetros medidos, bem como a avaliação da qualidade e confiabilidade desses resultados. Após essa avaliação preliminar optou-se por utilizar apenas as análises químicas dos poços tubulares de propriedade da Companhia Riograndense de Saneamento (CORSAN) e perfurados dentro do Programa de Açudes e Poços (PAP) da Secretaria de Obras do Estado do Rio Grande do Sul. Dessa maneira foram selecionadas 116 análises (Figura 2).

Complementando as informações foram realizadas coletas de água subterrânea em 30 poços (Figura 2), dos quais 7 poços captam água do SAG e 23 poços captam água do SASG. As amostras coletadas foram enviadas para o laboratório ECOCERTA Análises Ambientais Ltda que realizou a análise (APHA, 2005) dos seguintes parâmetros: alcalinidade, alumínio, antimônio, arsênio, bário, bicarbonato, chumbo, cloreto, cobre, cor, cromo, cádmio, cálcio, dureza total, ferro, fluoreto, fosfato, magnésio, manganês, mercúrio, nitrato, potássio, resíduo seco, selênio, silício, sódio, sólidos totais dissolvidos, sulfato, turbidez e zinco. As análises dos parâmetros condutividade, $\mathrm{pH}$ e temperatura foram realizadas em campo com o emprego de uma sonda multiparâmetros HQ40D. Além disso, foram coletadas amostras para avaliação bacteriológica (coliformes totais, fecais e bactérias heterotróficas).

A coleta das amostras de água subterrânea foi realizada na saída da tubulação ligada à bomba submersa, sempre após a purga do poço, geralmente após 20 minutos de bombeamento. Para cada poço foram coletadas amostras que foram acondicionadas em frascos plásticos (parâmetros físicos químicos) e num frasco do tipo borossilicato esterelizado (parâmetro microbiológico). Todas as amostras foram acondicionadas em caixas de isopor mantidas refrigeradas e transportadas, no mesmo dia da coleta, para o laboratório que realizou as análises. A validação dos resultados fornecidos pelo laboratório foi realizada com base no cálculo do balanço iônico, realizado com o emprego do programa Qualigraf (MOBUS, 2002). Esse programa calcula o erro prático (Ep) por meio da aplicação da metodologia definida por Custódio e Llamas (1983) e por Logan (1965) descritas em Feitosa et al. (2008). Foram aceitas as amostras que apresentaram erros inferiores a $10 \%$.

Os resultados das analises químicas foram tratados no programa Qualigraf (MOBUS, 2002) que possibilitou a elaboração dos diagramas de Piper e Stiff.

\section{CARACTERIZAÇÃO GEOLÓGICA E HI- DROGEOLÓGICA}

De acordo com o mapa geológico elaborado pela Companhia de Pesquisas e Recursos Minerais (CPRM, 1998), na área de estudo ocorrem diferentes tipos de rochas vulcânicas pertencentes à Formação Serra Geral, associadas a três unidades principais: Gramado, Palmas/Caxias e Várzea do Cedro (Figura 2).

Reginato e Strieder (2006b) identificam na região duas sequências de rochas vulcânicas: uma ácida e outra básica, dispostas em nove derrames principais. As rochas básicas pertencem a Unidade Gramado e são representadas por basaltos, constituindo seis derrames de lavas. Já as rochas ácidas (ocorrem sobre as rochas básicas) pertencem a Unidade Palmas/Caxias, e são caracterizadas pela ocorrência de riodacitos, dacitos e riolitos e formam três derrames principais. Associadas a estas sequencias ocorrem litologias representadas por brechas (mais comuns na sequência básica) e por níveis de vidro vulcânico (Unidade Várzea do Cedro). 


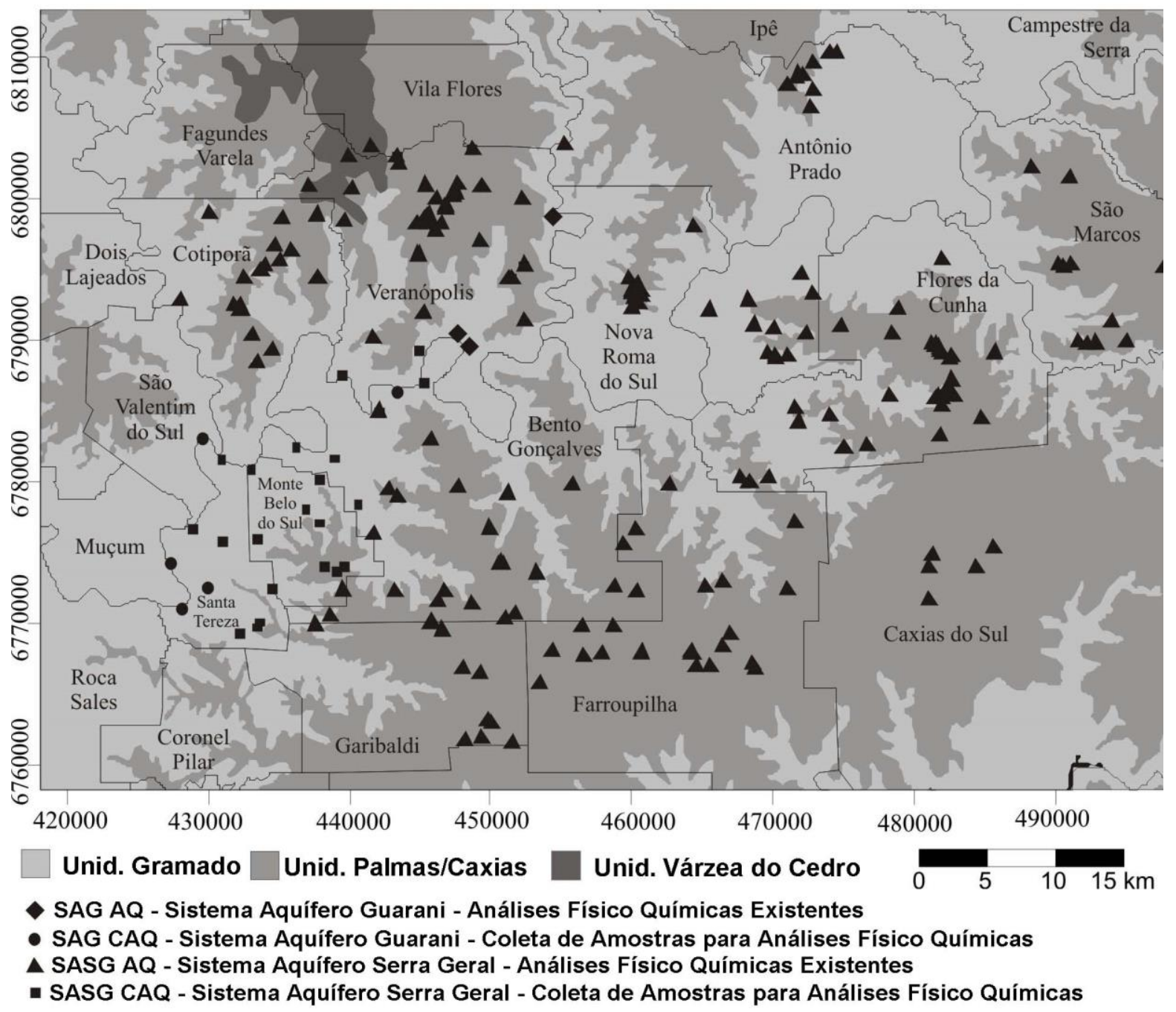

Figura 2 - Mapa geológico e localização dos poços tubulares utilizados na caracterização hidroquímica. Nos poços SAG CAQ e SASG CAQ foram realizadas as coletas e análises físico químicas das amostras de água subterrânea.

Figure 2 - Geological map and location of tubular wells used in hydrochemical characterization. The wells SAG CAQ e SASG CAQ were sampled for groundwater physical-chemical analysis.

Essas rochas apresentam estruturas tectônicas (fraturas e zonas de fraturas) e estruturas de resfriamento associadas aos diferentes derrames (zonas maciças, de brecha, vesiculares a amigdalóides, disjunção ou diáclases horizontais e verticais).

As rochas sedimentares da Formação Botucatu não afloram na área de estudo, sendo encontradas em profundidades variadas, alcançadas quando da perfuração de poços mais profundos. Essa unidade é constituída por arenitos quartzo feldspáticos de granulação fina a média, bem selecionados, de coloração avermelhada, rosada ou amarelo clara.

O SASG na região é caracterizado como um aquífero fraturado que possui diferentes comportamentos hidrogeológicos. Em geral, apresenta uma forte anisotropia, valores baixos de transmissividade, capacidade específica e vazão. A circulação de água no SASG ocorre nas estruturas tectônicas que apresentam abertura, junto às diferentes estruturas primárias e nos contatos entre os derrames (REGINATO, 2003; REGINATO E STRIEDER, 2006b e REGINATO et. al., 2010b). Machado e Freitas (2005) identificaram na região a ocorrência do Sistema Aquífero Serra Geral II, ao qual estão associados derrames de rochas vulcânicas da Unidade Hidroestratigráfica Serra Geral, e cujas litologias predominantes são riolitos e riodacitos da Unidade Palmas/Caxias e em menor proporção basaltos fraturados da Unidade Gramado. Em geral essa unidade apresenta capacidade específica inferior a $0,5 \mathrm{~m}^{3} / \mathrm{h} / \mathrm{m}$ (podendo chegar a $2 \mathrm{~m}^{3} / \mathrm{h} / \mathrm{m}$ em áreas com maior grau de fraturamento ou com arenitos na base) e salinidades baixas (inferiores a 250 $\mathrm{mg} / \mathrm{L})$. 
O SAG constitui um sistema aquífero poroso, granular associado às rochas sedimentares da Formação Botucatu, na região de estudo. Como esse sistema aquífero é recoberto pelos derrames de rochas vulcânicas da Formação Serra Geral, o mesmo encontra-se confinado, apresentando diferentes graus de confinamento. Segundo Machado e Freitas (2005) esse sistema aquífero nas regiões confinadas apresenta capacidades específicas superiores a $4 \mathrm{~m}^{3} / \mathrm{h} / \mathrm{m}$ e sólidos totais dissolvidos entre 250 e $400 \mathrm{mg} / \mathrm{L}$. Segundo Giardin e Faccini (2010) as águas que circulam pelas rochas sedimentares da Formação Botucatu em regiões mais confinadas, podem apresentar um conteúdo de sais totais variável entre 800 e 2000 $\mathrm{mg} / \mathrm{L}$. Já nas regiões onde o SAG não é confinado Machado e Freitas (2005), identificaram águas subterrâneas com valores menores para diferentes parâmetros, como sólidos totais dissolvidos (menor que $250 \mathrm{mg} / \mathrm{L}$ ) e alcalinidade total (menor que $100 \mathrm{mg} / \mathrm{L}$ ).

\section{RESULTADOS E DISCUSSÕES}

A análise dos dados dos poços tubulares cadastrados na região, evidencia a ocorrência de dois sistemas aquíferos denominados como SASG (Sistema Aquífero Serra Geral) e SAG (Sistema Aquífero Guarani).

As águas subterrâneas associadas ao SASG circulam em diferentes profundidades, pelas descontinuidades (tectônicas e de resfriamento) presentes nas rochas vulcânicas ácidas (riodacitos) e básicas (basaltos) da Formação Serra Geral.

Como essas águas circulam em diferentes níveis, que estão associados a derrames vulcânicos com composições químicas variadas (rochas ácidas e básicas), elas podem apresentar diferentes características hidroquímicas. Além disso, nas regiões onde há menor espessura de rochas vulcânicas e a existência de descontinuidades, há a possibilidade de conexão entre as águas que circulam no SAG e no SASG, ocasionando alterações no padrão hidroquímico.

Os poços que captam água do SAG apresentam diferentes profundidades, entre 100 metros nas regiões com menor espessura de rochas vulcânicas até 630 metros nas regiões de maior espessura. Além disso, foi possível identificar que o SAG ocorre na região em altitudes de -32 metros na porção da calha do Rio das Antas, principalmente nas regiões de Santa Tereza, Monte Belo do Sul, Cotiporã, Veranópolis e Bento Gonçalves. Para o norte em direção a Nova Prata há um aprofundamento do SAG que passa a ser encontrado na altitude de -162 metros. Para a direção de Carlos Barbosa e Caxias do Sul o SAG ocorre em níveis, mais próximos de altitudes positivas, sendo influenciado pelo controle tectônico.

\section{Características Hidroquímicas das Águas Sub- terrâneas Associadas ao Sistema Aquífero Guarani (SAG) na Área de Estudo}

$\mathrm{Na}$ área de estudo, foram identificados 7 poços que captam água do SAG, perfurados nas regiões de Santa Tereza, Bento Gonçalves e Veranópolis. Esses poços possuem diferentes profundidades, entre 108 a 384 m e estão localizados em regiões com diferentes altitudes (entre 53 e $300 \mathrm{~m})$.

As águas do SAG podem ser classificadas em três tipos principais, segundo o diagrama de Piper (Figura 3): bicarbonatadas sódicas, bicarbonatadas cálcicas ou magnesianas, e sulfatadas ou cloretadas sódicas.

A ocorrência desses três tipos hidroquímicos pode ser explicada, em função da localização geográfica desses poços, que representam diferentes graus de confinamento para a unidade. Nas regiões onde a espessura de rochas vulcânicas é menor (abaixo de 80 metros) há uma tendência de ocorrência das águas bicarbonatadas cálcicas ou magnesianas, enquanto que nas regiões onde há maior espessura de rochas vulcânicas (acima de 100 metros) há ocorrência dos campos das águas bicarbonatadas sódicas e sulfatadas ou cloretadas sódicas. Deve-se destacar que esse comportamento também pode sofrer influência de sistemas de fraturas, que podem favorecer a recarga e a mistura de águas com o SASG que tem maior proporção de águas bicarbonatadas cálcicas ou magnesianas.

Na figura 4 é apresentado um modelo conceitual hidrogeológico para os dois sistemas aquíferos (SAG e SASG) para a área de estudo. Nessa figura o poço P1 representaria a situação onde é mais comum a ocorrência de águas cálcicas ou magnesianas. Já os poços P3 e P10 representariam situações onde haveria uma maior tendência da ocorrência de águas bicarbonatadas sódicas e sulfatadas ou cloretadas sódicas. 


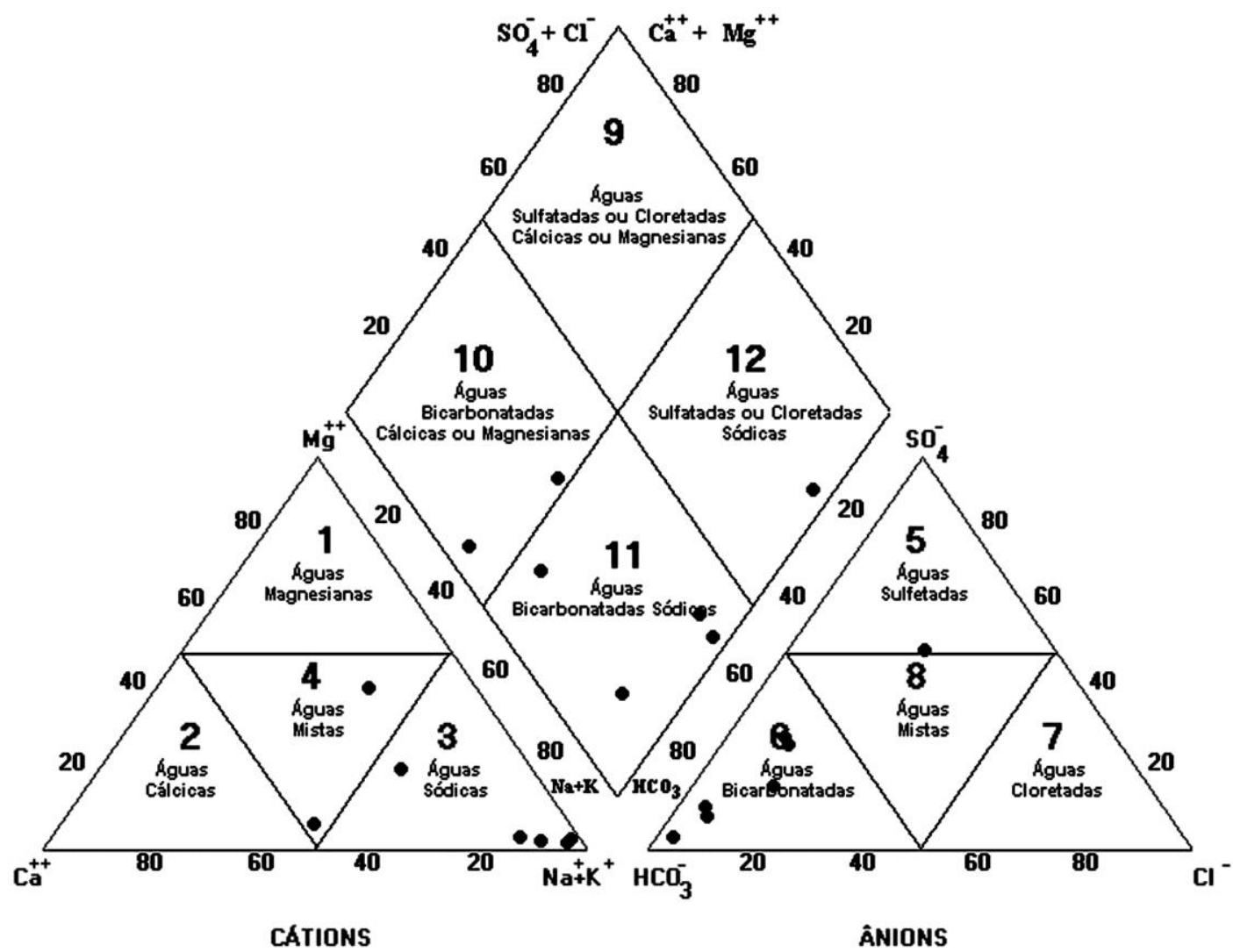

Figura 3 - Diagrama Piper com a representação dos tipos de águas subterrâneas do SAG na região de Santa Tereza, Bento Gonçalves e Veranópolis.

Figure 3 - Piper diagram showing the representation of groundwater chemical types from SAG in the Santa Tereza, Bento Gonçalves and Veranópolis region.

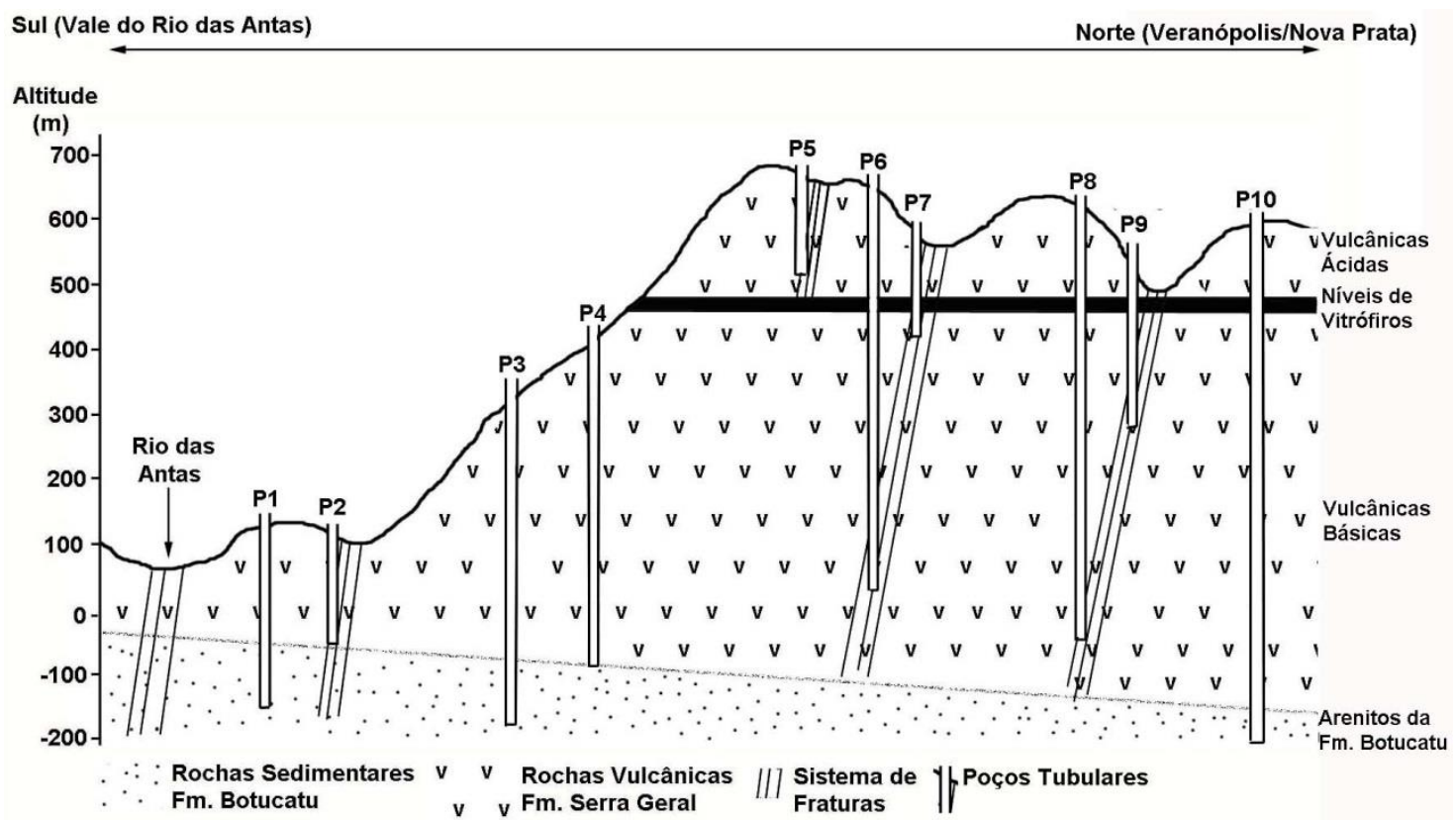

Figura 4 - Modelo conceitual dos dois sistemas aquíferos (SASG e SAG) e a relação de poços tubulares que captam água desses dois sistemas.

Figure 4 - Conceptual model of the two aquifer systems (SASG and SAG) and the relation of tubular wells between these two systems. 
Essa variação do padrão hidroquímico foi identificada também por Machado e Freitas (2005) e Machado (2005). Segundo esses autores, as águas do SAG nas regiões de maior confinamento, tendem a apresentar uma maior concentração de sais, sendo que as águas tendem a ser sódicas podendo evoluir para águas sulfatadas ou cloretadas.

Na figura 5 é apresentado o diagrama de Stiff onde pode ser observada a existência de padrões geométricos distintos.

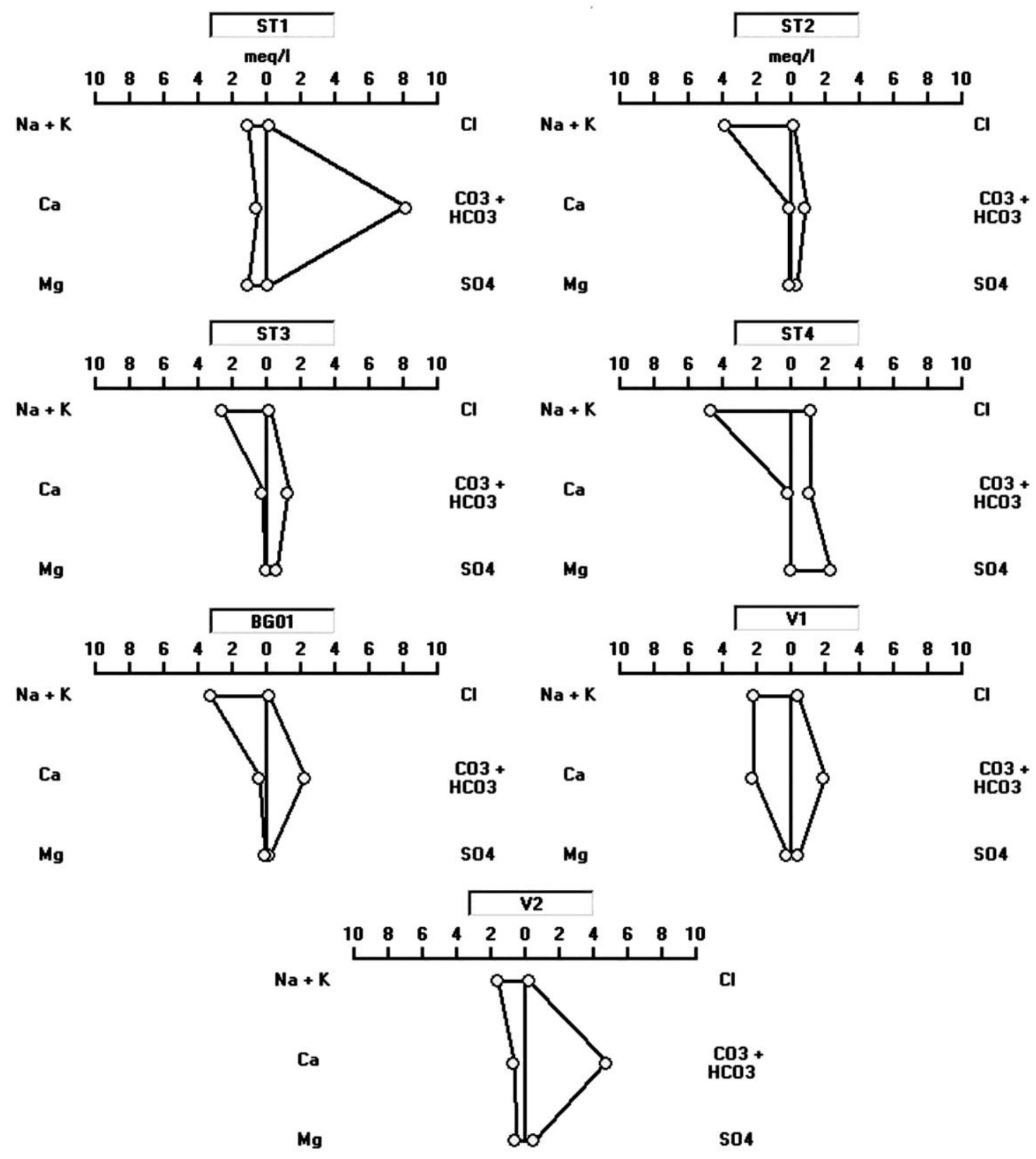

Figura 5 - Diagrama de Stiff com a representação dos diferentes grupos hidroquímicos das amostras de água subterrânea do SAG.

Figure 5 - Stiff diagram with the representation of different hydrochemical classes of groundwater samples from the SAG. 
A geometria apresentada pelas amostras ST1 e V1 é típica do campo das águas bicarbonatas cálcicas ou magnesianas. A diferença existente entre as formas está relacionada a uma maior tendência para a concentração de sódio e potássio (amostra V1), bem como de bicarbonato e carbonatos (amostra ST1). A geometria apresentada pelas amostras ST2, ST3 e BG01 é típica do campo das águas bicarbonatadas sódicas, sendo marcada pela maior concentração de sódio e potássio. A amostra V2, com base no Diagrama de Piper, foi classificada como bicarbonatada sódica, no entanto, sua geometria é semelhante a da amostra ST1. Nesse caso, o poço onde foi captada a amostra V2 está localizado numa região onde há uma maior espessura de rochas vulcânicas (110 metros). Já a geometria apresentada pela amostra ST4 é indicativa do campo das águas sulfatadas ou cloretadas sódicas. Essa amostra (ST4) foi coletada de um poço, localizado em áreas onde o SAG, apresenta um maior grau de confinamento.

Os dados da tabela 1, indicam que as águas subterrâneas do SAG tendem a apresentar valores mais elevados de $\mathrm{pH}(7,9$ a 9,6$)$ e de condutividade elétrica (270 a $686 \mathrm{uS} / \mathrm{cm})$. A explicação para essa ocorrência pode estar relacionada com uma circulação mais lenta, que favorece um maior contato com a rocha e uma maior concentração de elementos químicos. Isso também poderia explicar a ocorrência de uma maior concentração de sódio, bicarbonatos e carbonatos, bem como de cloretos e sulfatos.

Tabela 1 - Principais parâmetros físico químicos, das 30 amostras de água subterrânea, coletadas em poços tubulares associados ao SASG e SAG, na região de Santa Tereza, Monte Belo do Sul, Bento Gonçalves e Veranópolis.

Table 1 - Major physical chemical parameters of the 30 groundwater samples collected in tubular wells, associated with de SASG e SAG, in the Santa Tereza, Monte Belo do Sul, Bento Gonçalves e Veranópolis region.

\begin{tabular}{|c|c|c|c|c|c|c|c|c|c|c|c|}
\hline $\begin{array}{l}\text { Sistema } \\
\text { Aquifero }\end{array}$ & $\begin{array}{l}\text { Ponto } \\
\text { Poço }\end{array}$ & $\begin{array}{l}\text { Prof. } \\
\text { (m) }\end{array}$ & $\begin{array}{c}\mathrm{Ca} \\
(\mathrm{mg} / \mathrm{L})\end{array}$ & $\begin{array}{c}\mathrm{Mg} \\
(\mathrm{mg} / \mathrm{L})\end{array}$ & $\begin{array}{c}\mathrm{K} \\
(\mathrm{mg} / \mathrm{L})\end{array}$ & $\begin{array}{c}\mathrm{Na} \\
(\mathrm{mg} / \mathrm{L})\end{array}$ & $\begin{array}{c}\mathrm{Cl} \\
(\mathrm{mg} / \mathrm{L})\end{array}$ & $\begin{array}{c}\mathrm{SO}_{4} \\
(\mathrm{mg} / \mathrm{L})\end{array}$ & $\begin{array}{c}\text { Alcalin. } \\
\text { (mg/L) }\end{array}$ & $\mathrm{pH}$ & $\begin{array}{c}\mathrm{CE} \\
(\mathrm{uS} / \mathrm{cm})\end{array}$ \\
\hline SASG & BG04 & 175 & 14,7 & 8,67 & 0,3 & 20,10 & 6,13 & 6 & 118,8 & 8,2 & 288 \\
\hline SASG & BG05 & 54 & 14,6 & 14 & 1,6 & 16,30 & 8,01 & 5,0 & 163,35 & 7,3 & 359 \\
\hline SASG & BG06 & 110 & 13,6 & 9,4 & 0,6 & 20,40 & 2,36 & 2 & 163,35 & 7,8 & 341 \\
\hline SASG & BG07 & 150 & 5,32 & 5,05 & 0,3 & 16,5 & 6,13 & 2 & 118,8 & 7,9 & 268 \\
\hline SASG & MB01 & 66 & 4,7 & 4,2 & 1,3 & 27,3 & 2,36 & 11 & 118,8 & 7,2 & 281 \\
\hline SASG & MB02 & 126 & 8,6 & 4,6 & 1,4 & 60,80 & 18,39 & 64 & 128,7 & 7,8 & 498 \\
\hline SASG & MB03 & 68 & 5 & 2,6 & 1,6 & 19,5 & 6,6 & 4 & 74,25 & 6,9 & 175,1 \\
\hline SASG & MB04 & 136 & 6,5 & 1,9 & 2 & 19,6 & 8,01 & 2 & 69,3 & 7 & 162,4 \\
\hline SASG & MB05 & 150 & 3,9 & 2,2 & 3 & 12,70 & 12,73 & 1 & 59,4 & 6,7 & 145,8 \\
\hline SASG & MB06 & 136 & 1,8 & 0,46 & 1,6 & 29,1 & 4,71 & 5 & 74,25 & 7,3 & 165,7 \\
\hline SASG & MB07 & 168 & 4,5 & 1,3 & 6,2 & 14,5 & 10,37 & 3 & 39,6 & 6,3 & 167,1 \\
\hline SASG & MB08 & 150 & 2,6 & 0,13 & 6,2 & 15,5 & 8,49 & 2 & 39,6 & 6,3 & 129 \\
\hline SASG & V01 & 120 & 2,15 & 0,97 & 6,1 & 25,50 & 4,24 & 2 & 44,55 & 6,8 & 112,7 \\
\hline SASG & V02 & 150 & 1,46 & 1,34 & 4,7 & 7,3 & 3,30 & 1 & 9,90 & 5,8 & 44,1 \\
\hline SASG & V03 & 155 & 2,71 & 1,97 & 9,7 & 12 & 2,83 & 2 & 29,7 & 6,7 & 80,8 \\
\hline SASG & V04 & 424 & 1,96 & 1,82 & 9,7 & 11,9 & 3,77 & 1 & 49,5 & 6,8 & 80 \\
\hline SASG & V05 & 110 & 9,38 & 3,16 & 4,9 & 13,60 & 1,41 & 1 & 59,4 & 7 & 107,6 \\
\hline SASG & ST02 & 78 & 10,9 & 12,7 & 2,30 & 29,4 & 1,88 & 3 & 138,6 & 7,8 & 342 \\
\hline SASG & ST03 & 85 & 4,5 & 0,02 & 5,1 & 43,10 & 2,35 & 2 & 94,05 & 8 & 192,5 \\
\hline SASG & ST04 & 156 & 10,2 & 0 & 0,5 & 16,10 & 4,24 & 3 & 113,85 & 7,7 & 277 \\
\hline SASG & ST06 & 105 & 2 & 7 & 0,5 & 31,10 & 8,49 & 5 & 128,7 & 7,5 & 400 \\
\hline SASG & ST07 & 180 & 2,5 & 0 & 0,25 & 45,75 & 0,47 & 2 & 14,85 & 9,9 & 146,5 \\
\hline SASG & ST08 & 44 & 18,9 & 7,9 & 4,60 & 16,35 & 2,36 & 2 & 54,45 & 7,2 & 144 \\
\hline SASG & ST09 & 187 & 15,5 & 7,5 & 0,5 & 16,5 & 3,30 & 4 & 123,75 & 7,8 & 292 \\
\hline SAG & ST1 & 109 & 10,5 & 13,3 & 0,6 & 24,10 & 7,07 & 6 & 168,3 & 7,9 & 386 \\
\hline SAG & ST2 & 108 & 1 & 0,5 & 0,7 & 87,20 & 6,13 & 18 & 113,85 & 9 & 403 \\
\hline SAG & ST3 & 110 & 4,2 & 0,13 & 0,60 & 59,35 & 7,54 & 28 & 54,45 & 9,1 & 270 \\
\hline
\end{tabular}


Tabela 1 - Principais parâmetros físico químicos, das 30 amostras de água subterrânea, coletadas em poços tubulares associados ao SASG e SAG, na região de Santa Tereza, Monte Belo do Sul, Bento Gonçalves e Veranópolis.

Table 1 - Major physical chemical parameters of the 30 groundwater samples collected in tubular wells, associated with de SASG e SAG, in the Santa Tereza, Monte Belo do Sul, Bento Gonçalves e Veranópolis region.

\begin{tabular}{cccccccccccc}
\hline $\begin{array}{c}\text { Sistema } \\
\text { Aquifero }\end{array}$ & $\begin{array}{c}\text { Ponto } \\
\text { Poço }\end{array}$ & $\begin{array}{c}\text { Prof. } \\
(\mathrm{m})\end{array}$ & $\begin{array}{c}\mathrm{Ca} \\
(\mathrm{mg} / \mathrm{L})\end{array}$ & $\begin{array}{c}\mathrm{Mg} \\
(\mathrm{mg} / \mathrm{L})\end{array}$ & $\begin{array}{c}\mathrm{K} \\
(\mathrm{mg} / \mathrm{L})\end{array}$ & $\begin{array}{c}\mathrm{Na} \\
(\mathrm{mg} / \mathrm{L})\end{array}$ & $\begin{array}{c}\mathrm{Cl} \\
(\mathrm{mg} / \mathrm{L})\end{array}$ & $\begin{array}{c}\mathrm{SO}_{4} \\
(\mathrm{mg} / \mathrm{L})\end{array}$ & $\begin{array}{c}\text { Alcalin. } \\
(\mathrm{mg} / \mathrm{L})\end{array}$ & $\begin{array}{c}\text { pH } \\
(\mathrm{uS} / \mathrm{cm})\end{array}$ \\
\hline SAG & ST4 & 126 & 2,4 & 0,11 & 1 & 105,9 & 41,49 & 114 & 55,55 & 9,6 & 686 \\
SAG & BG01 & 210 & 13,2 & 6,4 & 0,4 & 35,30 & 9,43 & 25 & 128,7 & 8,0 & 382 \\
SAG & V1 & 384 & 44 & 2,67 & 4,87 & 47 & 14,4 & 20 & 120 & 8,1 & 436 \\
SAG & V2 & 95 & 13,2 & 6,4 & 0,4 & 35,30 & 9,43 & 25 & 128,7 & 8 & 382 \\
\hline
\end{tabular}

Características Hidroquímicas das Águas Subterrâneas Associadas ao Sistema Aquífero Serra Geral (SASG) na Área de Estudo

A avaliação geral da classificação das águas subterrâneas que circulam pelo SASG foi realizada com base na análise das amostras provenientes de 116 poços tubulares (amostras selecionadas do cadastro da CORSAN e do

PAP). O diagrama de Piper (Figura 6) evidencia a presença de três diferentes tipos de águas: bicarbonatadas cálcicas ou magnesianas, bicarbonatadas sódicas e sulfatadas cálcicas ou magnesianas, esse último tipo, com ocorrência restrita.

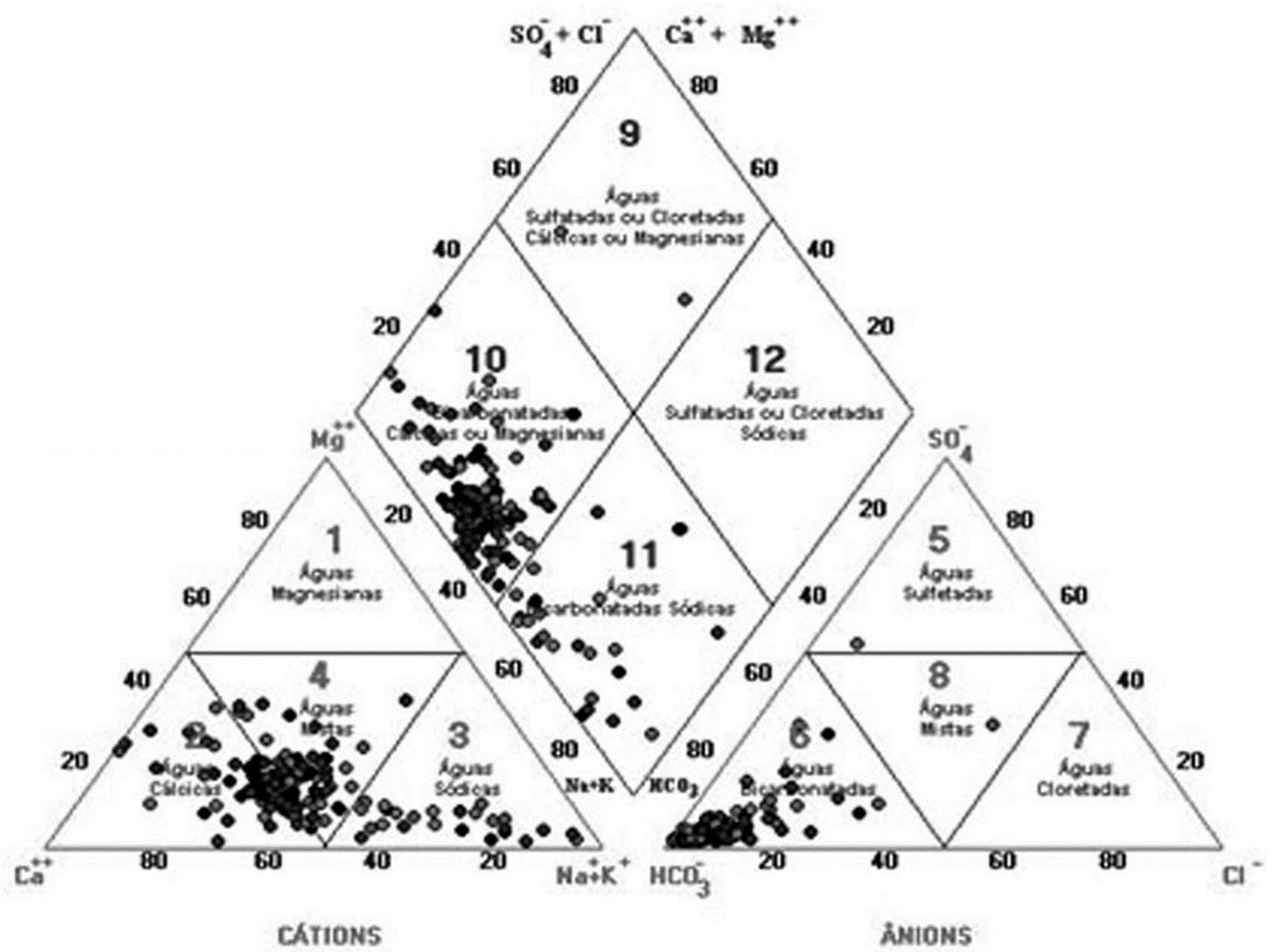

Figura 6 - Diagrama de Piper com a representação dos três tipos de águas subterrâneas no Sistema Aquífero Serra Geral (SASG).

Figure 6 - Piper diagram with the representation of the three hydrochemical classes of groundwater in the Serra Geral Aquifer System (SASG). 
Uma avaliação detalhada foi realizada com base em 23 amostras coletadas em poços que captam água do SASG, localizados na região de Santa Tereza, Monte Belo do Sul, Bento Gonçalves e Veranópolis (Figura 2). Nessa região, os poços possuem diferentes profundidades (entre
54 e 424 m) e estão localizados em regiões com diferentes altitudes (entre 93 e $680 \mathrm{~m}$ ).

A classificação das águas apresentadas no diagrama de Piper (Figura 7) indica a ocorrência de dois grandes grupos: águas bicarbonatadas cálcicas ou magnesianas e águas bicarbonatadas sódicas.

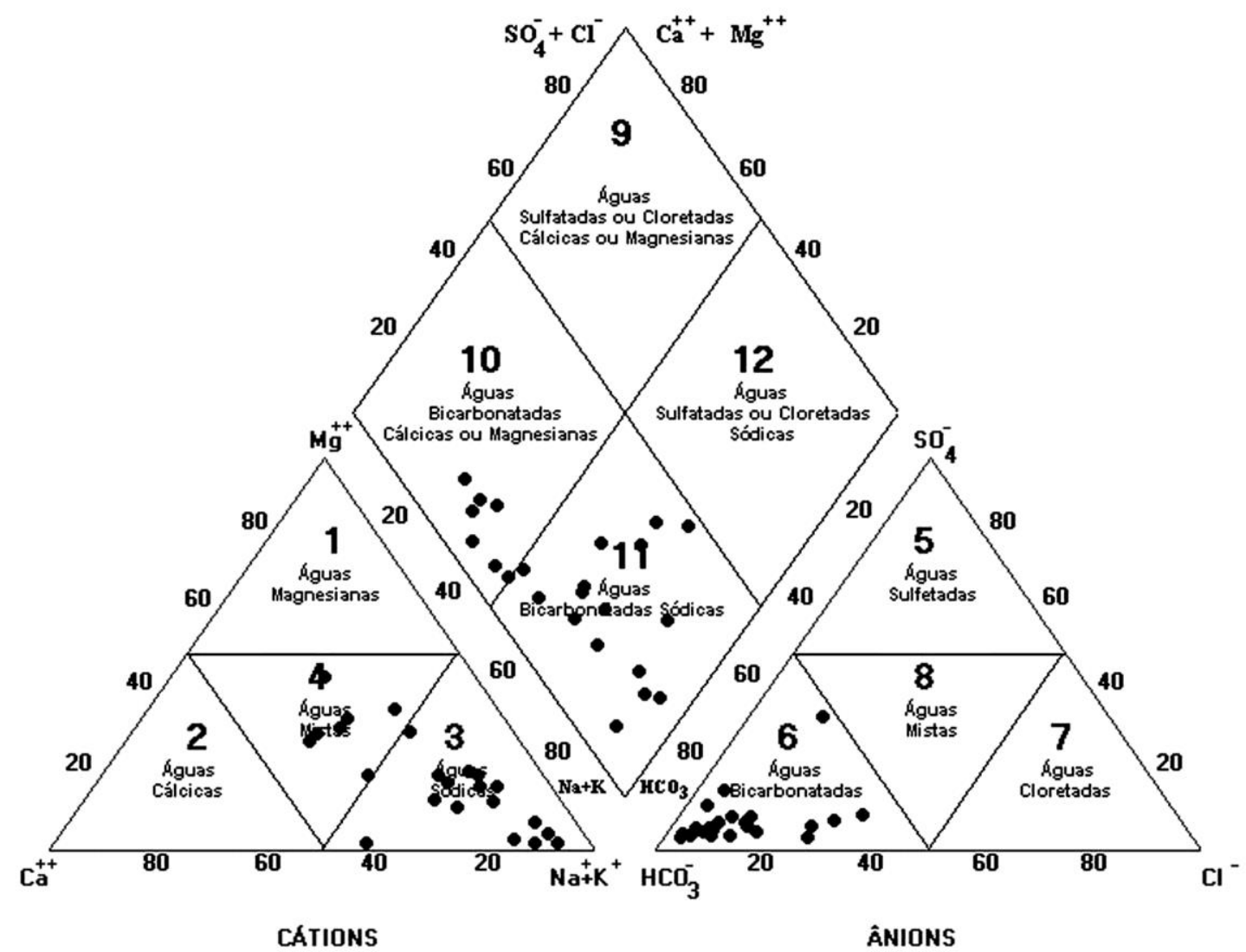

Figura 7 - Diagrama Piper com a representação dos tipos de águas subterrâneas do SASG na região de Santa Tereza, Monte Belo do Sul, Bento Gonçalves e Veranópolis.

Figure 7 - Figure 7 - Piper Diagram with the representation of the hydrochemical classes of groundwater from SASG in the Santa Tereza, Monte Belo do Sul, Bento Gonçalves and Veranópolis region.

Segundo Reginato et. al. (2010a) as águas do SASG são principalmente bicarbonatadas cálcicas ou magnesianas representando a composição química das rochas vulcânicas que formam o sistema aquífero, sendo que a fonte original dos elementos cálcio, magnésio e sódio está associada a alteração dos silicatos presentes nessas rochas. Conforme Lisboa (1996), o SASG tende a apresentar uma relação onde o $\mathrm{Ca}>\mathrm{Mg}>\mathrm{Na}$ e um enriquecimento de cálcio e magnésio do topo (rochas ácidas) para a base (rochas básicas) do pacote de rochas vulcânicas. Segundo Machado e Freitas (2000) esse padrão está associado às primeiras fases de evolução geoquímica das águas que circulam no SASG. Para Bittencourt et. al. (2003) as águas bicarbo- natadas cálcicas são as águas típicas do SASG, sendo o cálcio o cátion mais abundante, proveniente da alteração de plagioclásios e minerais ferromagnesianos dos basaltos.

$\mathrm{Na}$ figura 4, que representa o modelo conceitual dos aquíferos na área de estudo, os poços P5, P7 e P9 representam o campo das águas bicarbonatadas cálcicas ou magnesianas. Como eles estão localizados em diferentes sequências vulcânicas (ácidas e básicas) e possuem diferentes profundidades, vão apresentar concentrações distintas para os elementos cálcio, magnésio e sódio. $\mathrm{O}$ poço $\mathrm{P} 5$ representa a situação onde teremos menores concentrações desses elementos, refletindo nos menores valores de condutividade (abaixo de $100 \mathrm{uS} / \mathrm{cm}$ ) e pH abaixo de 7. 
Essas características podem ser explicadas pela existência de uma maior recarga e circulação da água subterrânea rasa, favorecendo assim a renovação e a baixa concentração de elementos.

O campo das águas bicarbonatadas sódicas não é comum no SASG nessa região, portanto poderia evidenciar duas situações. A primeira estaria relacionada com o maior confinamento do SASG, enquanto a segunda está relacionada a possível existência de conexão entre o SAG e o SASG. Lisboa (1996) sugere que esse padrão é resultado da conexão e mistura de águas do SAG com o SASG. Machado e Freitas (2000) sugerem que esse campo pode estar relacionado a uma evolução natural da geoquímica ou pode evidenciar a ocorrência de conexão entre os dois sistemas aquíferos. Bittencourt et. al. (2003) sugere que essas águas são provenientes de aquíferos subjacentes ao SASG, como o SAG. Para Mocellin e Ferreira (2009) águas do SASG que não são bicarbonatadas cálcicas ou magnesianas representam diferentes taxas de misturas de águas provenientes de aquíferos sotopostos ao SASG.

$\mathrm{Na}$ figura 4, os poços P2, P4, P6 e P8, representariam o campo das águas bicarbonatadas sódicas. Os poços P2 e P4 estão localizados em regiões com menor espessura de rochas vulcânicas e apresentam entradas de água próximas do SAG. Em função disso, haveria a possibilidade de conexão entre os dois aquíferos, proporcionando o aumento dos teores de sódio, potássio, cloretos e sulfatos. Os poços P6 e P8 estão associados a estruturas tectônicas presentes nas rochas vulcânicas, sendo que a explicação para a ocorrência desse tipo de água está associada a um maior grau de confinamento ou a ocorrência de conexão originada através da interceptação do SAG pelas fraturas.

Com base no diagrama de Stiff (Figuras 8 e 9) podem ser evidenciadas geometrias típicas das águas do SASG e das águas que sugerem a existência de conexão com o SAG. Na figura 8 são apresentadas as geometrias típicas das águas subterrâneas que circulam pelos aquíferos fraturados que não apresentam conexão com o SAG (amostras ST02, ST08, BG06, ST09, BG04, BG05). Essas águas, em geral, apresentam concentrações variáveis de cálcio, magnésio e sódio e, pequenas concentrações de cloretos e sulfatos. A concentração de carbonatos e bicarbonatos são baixas, mas nas regiões onde os poços tubulares interceptam porções mais profundas do SASG há um aumento na concentração desses elementos. Isso pode estar relacionado a um maior grau de confinamento ou a presença de minerais de carbonato que ocorrem preenchendo fraturas ou vesículas (amígdalas).

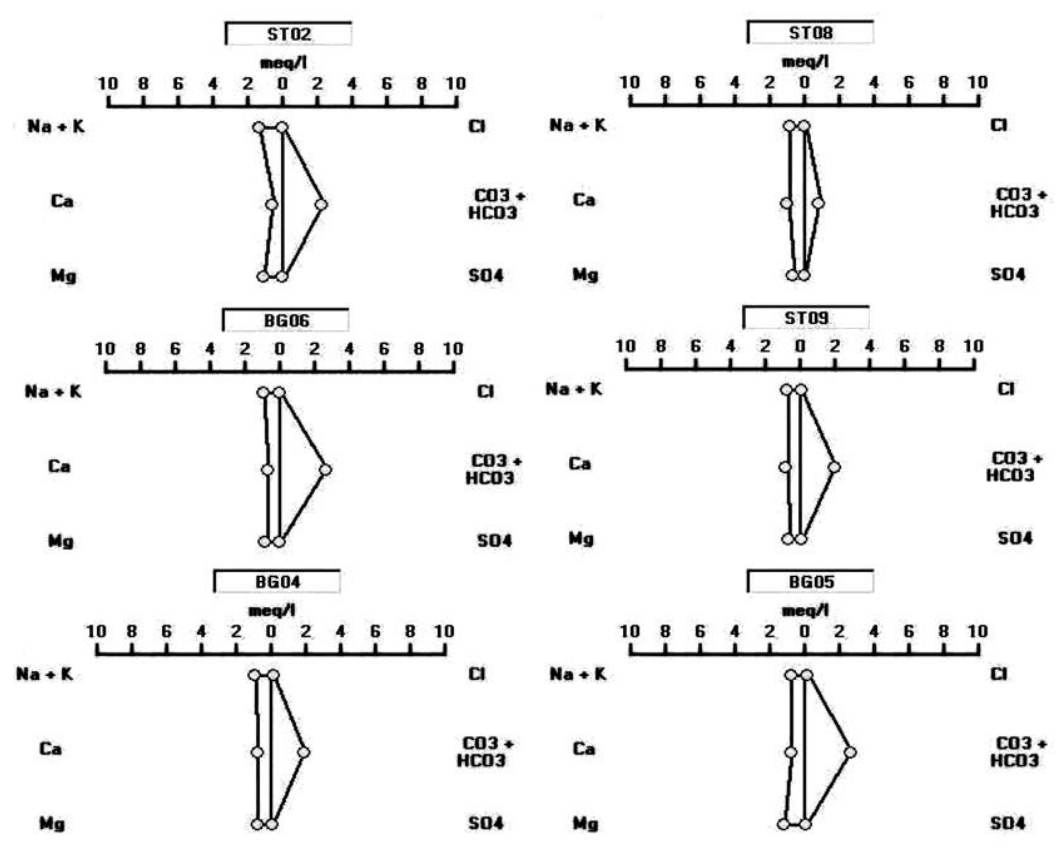

Figura 8 - Diagrama de Stiff das amostras de águas subterrâneas do SASG que não possuem conexão como o SAG, na região de Santa Tereza, Monte Belo do Sul, Bento Gonçalves e Veranópolis.

Figure 8 - Stiff diagram of groundwater samples from the SASG which doesn't present connection with the SAG, in the Santa Tereza, Monte Belo do Sul, Bento Gonçalves and Veranópolis region. 
$\mathrm{Na}$ figura 9 são apresentados os diagramas de Stiff típicos das águas subterrâneas que circulam pelos aquíferos fraturados e que sugerem a existência de conexão com o SAG (amostras MB01, MB02, MB03, MB04, ST07 e ST04). Essas águas, em geral, são caracterizadas por um aumento na concentração de sódio e potássio e, em algumas amostras, carbonatos e bicarbonatos. Além disso, a amostra MB02 apresenta a ocor- rência de uma concentração maior de sulfato (64 $\mathrm{mg} / \mathrm{L}$ ). Se compararmos os diagramas das amostras ST04, MB01, MB02 (Figura 9) com os diagramas ST2, ST3 e BG01 (Figura 5), observa-se uma semelhança na geometria. Isso poderia sugerir a existência de conexão entre os aquíferos, pois não é comum a ocorrência de maiores concentrações de sódio, potássio, cloretos e sulfatos nas águas que circulam no SASG.

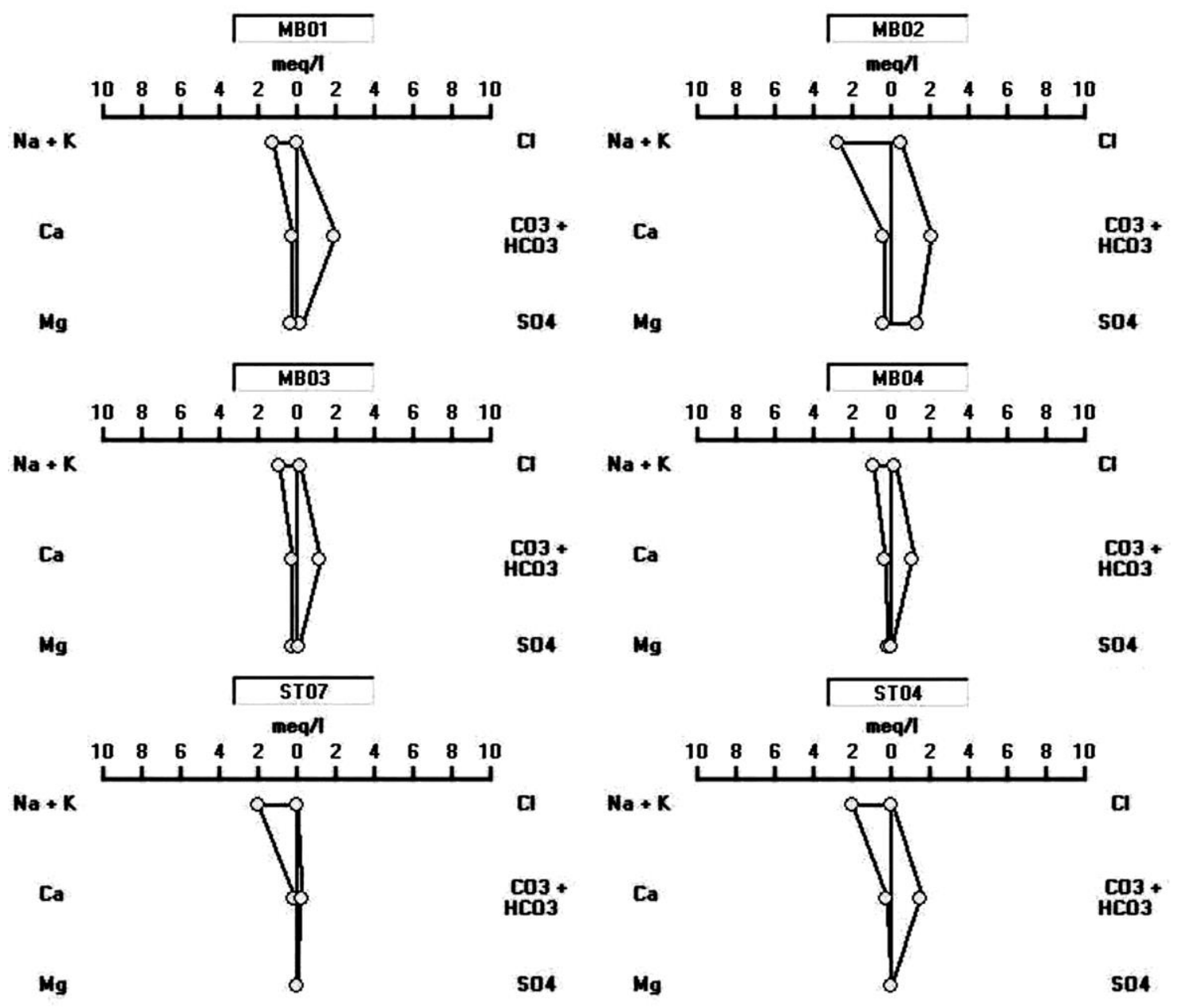

Figura 9 - Diagrama de Stiff das amostras de águas subterrâneas do SASG que sugerem a possibilidade de ocorrência da conexão como o SAG, na região de Santa Tereza, Monte Belo do Sul, Bento Gonçalves e Veranópolis.

Figure 9 - Stiff diagram of groundwater samples from the SASG suggesting the possibility of the connection as the SAG, in the Santa Tereza, Monte Belo do Sul, Bento Gonçalves and Veranópolis region.

$\mathrm{Na}$ análise dos dados físico químicos apresentados na tabela 1, fica evidenciada uma variação nos parâmetros $\mathrm{pH}$ e condutividade. Em geral valores de condutividade inferiores a 200 $\mathrm{uS} / \mathrm{cm}$ e de $\mathrm{pH}$ menores que 7,5 , estão associados a poços rasos. Já valores de condutividade (entre
200 e 498 uS/cm) e pH (entre 7,5 e 9,9) estão associados a poços mais profundos.

\section{CONCLUSÕES}

Na região de estudo há ocorrência do Sistema Aquífero Serra Geral (SASG) associado às 
rochas vulcânicas ácidas e básicas e do Sistema Aquífero Guarani (SAG). Na região o SAG é um aquífero confinado que é recoberto por pacotes de rochas vulcânicas com diferentes espessuras.

$\mathrm{Na}$ área de estudo o SAG é caracterizado pela ocorrência de três grupos principais de águas: bicarbonatadas sódicas, bicarbonatadas cálcicas ou magnesianas e sulfatadas ou cloretadas sódicas. A ocorrência desses três grupos está associada a diferenças no grau de confinamento provocado pelas variações nas espessuras do pacote de rochas vulcânicas, bem como pelos processos de recarga. Além disso, essas águas apresentaram valores mais elevados de $\mathrm{pH}(7,9$ a $9,6)$ e uma maior condutividade elétrica $(270$ a $686 \mathrm{uS} / \mathrm{cm})$.

O SASG na área de estudo é caracterizado pela ocorrência de três tipos de águas: bicarbonatadas cálcicas ou magnesianas, bicarbonatadas sódicas e sulfatadas cálcicas ou magnesianas. As águas bicarbonatas cálcicas ou magnesianas são típicas do SASG, sendo a fonte dos elementos cálcio, magnésio e sódio os silicatos presentes nas rochas vulcânicas ácidas (riodacitos) e básicas (basaltos). Os outros dois tipos (bicarbonatadas sódicas e sulfatadas cálcicas ou magnesianas) têm sua ocorrência, relacionada a um maior grau de confinamento ou a existência de misturas de águas provocadas pela conexão do SAG com o SASG. Além disso, as águas do SASG apresentam valores de condutividade entre 44 e 498 $\mathrm{uS} / \mathrm{cm}$ e $\mathrm{pH}$ entre 5,8 e 9,9.

A análise dos diagramas de Piper e Stiff das águas do SASG e SAG sugere a existência de uma possível conexão entre os dois aquíferos. Em geral, as águas do SASG, que não têm influência do SAG, apresentam concentrações variáveis de cálcio, magnésio, sódio, carbonatos, bicarbonatos e pequenas concentrações de cloretos e sulfatos. Por outro lado, águas com concentrações mais elevadas de sódio, potássio, cloretos e sulfatos, poderiam sugerir a existência de uma possível conexão entre os dois aquíferos.

A conexão entre o SAG e o SASG, sugerida pelas características hidroquímicas pode ser gerada, em função da presença de descontinuidades (presença de fraturas, falhas ou estruturas associadas aos derrames), por diferenças na carga hidráulica e favorecida pela pequena espessura dos derrames de rochas vulcânicas.

\section{AGRADECIMENTOS}

Os autores agradecem a Fundação de Amparo a Pesquisa do Estado do Rio Grande do Sul, pelo financiamento do projeto.

\section{REFERÊNCIAS}

APHA. Standard methods for the examination of water and wastewater. $21^{\mathrm{a}}$ Edition, Washingron, 2005.

BITTENCOURT, A.V.L.; ROSA FILHO, E.F.da R.; HIINDI, E.C.; BUCHMANN FILHO, A.C. A Influência dos Basaltos e de Misturas com Águas de Aquíferos Sotopostos nas Águas Subterrâneas do Sistema Aquífero Serra Geral na Bacia do Rio Piquiri, ParanáBR. Revista Águas Subterrâneas. ABAS. São Paulo. 17(1):67-75. 2003.

COMPANHIA DE PESQUISAS DE RECURSOS MINERAIS - CPRM. Mapeamento Geológico Integrado da Bacia Hidrográfica do Guaíba: Carta Geológica. Folha SH22-V-D-Caxias do Sul. Companhia de Pesquisas de Recursos Minerais. Porto Alegre. Mapa colorido. Escala 1:250.000. Material Cartográfico. 1998.

FEITOSA, F.A.C; MANOEL FILHO, J.; FEITOSA, E.C.; DEMETRIO, J.G. Hidrogeologia: conceitos e aplicações. 3ed. rev. e ampl. Rio de Janeiro. CPRM. LABHID. 2008. 812p.
GIARDIN, A.; FACCINI, U. Termalismo e Hidroquímica como Evidências de Limite de Fluxo Regional no Sistema Aquífero Guarani no Sul do Brasil. Revista Águas Subterrâneas. ABAS. São Paulo. 24(04):1-12. 2010.

LISBOA, N.A. Fácies, estratificações hidrogeoquímicas e seus controladores geológicos, em unidades hidrogeológicas do sistema aquífero Serra Geral, na bacia do Paraná, Rio Grande do Sul. 1996. 135p. Tese (Doutorado em Geociências) . Instituto de Geociências, Programa de Pós-Graduação em Geociências. Universidade Federal do Rio Grande do Sul. Porto Alegre.

MACHADO, J.L.F. Compartimentação Espacial e Arcabouço Hidroestratigráfico do Sistema Aquífero Guarani no Rio Grande do Sul. 2005. Tese (Doutorado em Geologia Sedimentar). Programa de PósGraduação em Geologia. UNISINOS. São Leopoldo, RS.

MACHADO, J.L.F.; FREITAS, M.A. de. Hidroquímica do Aquífero Serra Geral no Oeste de Santa Cata- 
rina. In: $1^{\circ} \mathrm{ST}$ JOINT WORLD CONGRESSO ON GROUNDWATER. 2000, Anais. Fortaleza. CdRoom.

MACHADO, J.L.F.; FREITAS, M.A. de. Projeto Mapa Hidrogeológico do Rio Grande do Sul: relatório final. Porto Alegre. CPRM. . 65p.mapa.2005.

MOBUS, G. QUALIGRAF - Programa para análise da qualidade da água. Fortaleza, FUNCENE - Fundação Cearense de Meteorologia e Recursos Hídricos. Software-CD. 2002.

MOCELLIN, R.C.; FERREIRA, F.J.F. Conectividade e Compartimentação dos Sistemas Aquíferos Serra Geral e Guarani no Sudoeste do Estado do Paraná, Brasil. Revista Brasileira de Geociências. 39(3):567579, setembro de 2009.

REGINATO, P.A.R. Integração de Dados para Prospecção de Aquíferos Fraturados em Trecho da Bacia Hidrográfica Taquari-Antas (RS). 2003. 254p. Tese (Doutorado em Engenharia). Escola de Engenharia, Programa de Pós-Graduação em Engenharia de Minas, Metalúrgica e dos Materiais (UFRGS), Porto Alegre.

REGINATO, P.A.R.; STRIEDER, A.J. Caracterização Estrutural dos Aquíferos Fraturados da Formação
Serra Geral na Região Nordeste do Estado do Rio Grande do Sul. Revista Brasileira de Geociências. 36(1):13-22, março de 2006a.

REGINATO, P.A.R.; STRIEDER, A.J Integração de Dados Geológicos na Prospecção de Aquíferos Fraturados na Formação Serra Geral. Revista Águas Subterrâneas. ABAS. São Paulo. 20(1):1-14. 2006 b.

REGINATO, P.A.R; AHLERT, S.; FINOTTI, A.R.; SCHNEIDER, V.E.; GILIOLI, K.C.. Qualidade das Águas Subterrâneas de Diferentes Aquíferos Associados à Formação Serra Geral na Região Nordeste do Estado do Rio Grande do Sul. In: CONGRESSO BRASILEIRO DE ÁGUAS SUBTERRÂNEAS XVI E ENCONTRO NACIONAL DE PERFURADORES DE POÇOS XVII. 2010a. Anais. São Luis, MA. CdRoom.

REGINATO, P.A.R.; AHLERT, S.; GILIOLI, K.C.. Hidrodinâmica de Diferentes Aquíferos Fraturados Associados à Formação Serra Geral na Região Nordeste do Estado do Rio Grande do Sul. In: CONGRESSO BRASILEIRO DE ÁGUAS SUBTERRÂNEAS XVI E ENCONTRO NACIONAL DE PERFURADORES DE POÇOS XVII. 2010b. Anais. São Luis, MA. CdRoom. 